\title{
ФИНАНСЫ
}

FINANCE

${ }^{1}$ Тимоничева И.Н., 2Яновский В.В., ${ }^{3}$ Бережной А.C.
УРОВЕНЬ ДОВЕРИЯ К БЕЗОПАСНОСТИ ФИНАНСОВЫХ ТЕХНОЛОГИЙ БАРЬЕР ИЛИ ТОЧКА РОСТА

${ }^{1}$ Главное управление Центрального банка Российской Федерации по Центральному федеральному округу, ул. Балчуг, 2, Москва, 115035, Россия

${ }^{2}$ Отделение по Белгородской области Главного управления Центрального банка

Российской Федерации по Центральному федеральному округу, проспект Славы, 74, Белгород, 308000, Россия

${ }^{3}$ Отделение по Белгородской области Главного управления Центрального банка

Российской Федерации по Центральному федеральному округу, проспект Славы, 74, Белгород, 308000, Россия

\begin{abstract}
Аннотация
В статье обосновывается важность показателя уровня доверия к безопасности финансовых технологий, способного выступать как барьером, так и точкой роста их использования. Рассматриваются некоторые результаты всероссийского опроса граждан и бизнеса, проведенного Банком России в 2021 году с целью оценки уровня доверия к безопасности финансовых технологий и сервисов. Раскрываются основные направления работы Банка России по преодолению имеющихся барьеров и формированию высокого уровня доверия к безопасности финансовых технологий. Сделаны выводы о важности координации усилий, направленных на повышение киберграмотности населения. Необходимо отметить, что точка зрения авторов настоящей статьи может и не совпадать с официальной позицией Банка России.
\end{abstract}

Ключевые слова: финансовые технологии, доверие, кибербезопасность, Банк России, цифровая грамотность

Информация для цитирования: Тимоничева И.Н., Яновский В.В., Бережной А.С. Уровень доверия к безопасности финансовых технологий - барьер или точка роста // Научный результат. Экономические исследования. 2021. Т.7. № 3. C. 81-88. DOI: 10.18413/2409-1634-2021-7-3-0-7 
Irina N. Timonicheva, Vladimir V. Yanovskiy, Anatoly S. Berezhnoy

\section{THE LEVEL OF CONFIDENCE IN THE SAFETY OF FINANCIAL TECHNOLOGIES - A BARRIER OR A POINT OF GROWTH}

${ }^{1}$ Main Directorate of the Central Bank of the Russian Federation for the Central Federal District, st. Balchug, 2, Moscow, 115035, Russia

${ }^{2}$ Branch for the Belgorod Region of the Main Directorate of the Central Bank of the Russian Federation for the Central Federal District, Slavy Avenue, 74, Belgorod, 308000, Russia

${ }^{3}$ Branch for the Belgorod Region of the Main Directorate of the Central Bank of the Russian Federation for the Central Federal District, Slavy Avenue, 74, Belgorod, 308000, Russia

\begin{abstract}
The article substantiates the importance of the existing level of trust in the security of financial technologies, which can act as both a barrier and a point of growth for their use. Some results of an all-Russian survey of citizens and businesses conducted by the Bank of Russia in 2021 to assess the level of confidence in the security of financial technologies and services are considered. The main areas of work of the Bank of Russia aimed at overcoming existing barriers and creating a high level of confidence in the security of financial technologies are outlined. Conclusions are made about the importance of coordinating efforts at the regional level aimed at increasing the cyber literacy of the population. It should be noted that the point of view of the authors of this article may not coincide with the official position of the Central Bank of the Russian Federation.
\end{abstract}

Key words: inancial technology, trust, cybersecurity, Bank of Russia, digital literacy

Information for citation: Timonicheva I.N., Yanovskiy V.V., Berezhnoy A.S. -The level of confidence in the safety of financial technologies - a barrier or a point of growth", Research Result. Economic Research, 7(3), 81-88, DOI: 10.18413/2409-16342021-7-3-0-7

\section{Введение}

Сегодня финансовые технологии становятся неотъемлемой частью всех видов финансовых услуг, включая кредитование, платежи и переводы, сбережения, инвестирование и страхование. Цифровизация на глазах меняет ландшафт финансового мира, а темпы технологических изменений неуклонно нарастают. Только за 2015 - 2019 годы уровень проникновения новых технологий в финансовый сектор, согласно экспертным оценкам, вырос в 4 раза, достигнув $64 \%$ на глобальном уровне и более $80 \%$ в России [Стратегия развития национальной платежной системы на 20212023 годы]. По данному показателю наша страна входит в тройку мировых лидеров и занимает первое место по росту числа безналичных транзакций.
Высокие темпы развития и внедрения информационных технологий, с одной стороны, положительно влияют на конкурентную среду и позволяют увеличить скорость, доступность, удобство финансовых услуг для потребителей. Это достигается прежде всего за счет нивелирования физических расстояний между клиентами и финансовыми организациями, а также за счет сокращения издержек и расширения ассортимента.

С другой стороны, наличие киберрисков, риска утраты контроля за сохранностью персональных данных, неуклонный рост требований к цифровым знаниям и необходимость их периодической актуализации вследствие опережающего роста финансовых технологий могут отрицательно сказаться на ментальной доступно- 
сти финансовых услуг, и, в конечном итоге, на доверии граждан к финансовым инновациям.

Цель работы. Уровень доверия к безопасности финансовых технологий способен выступать как барьером, так и точкой роста их использования. Как правило, высокий уровень доверия способствует трансформации потребительского выбора в пользу более широкого использования новых технологий. Низкий уровень напротив - ограничивает этот процесс. В этой связи, исследование вопроса доверия к безопасности финансовых технологий не только находится в практической плоскости, отражая запрос участников финансовго рынка, но и несет в себе несомненный научный интерес, основанный на актуальности и дискуссионном характере этого вопроса. Все это обусловило цель работы представить некоторые результаты исследования Банка Росиии по доверию к безопасности финансовых технологий и сервисов, привлечь внимание научного сообщества к затрагиваемой в работе проблематике.

В качестве аналитического материала в работе использовались результаты исследования, выполненого на данных первого всероссийского опроса населения и бизнеса по доверию к безопасности финансовых технологий и сервисов, проведенного Банком России в 2021, а также результаты исследования цифровой грамотности россиян, проведенного в 2021 году Национальным агентством финансовых исследований (НАФИ). В работе использовалась статистическая информация, представленная на официальном сайте Банка России.

Автором применялись общенаучные методы теоретического исследования такие, как индукция, дидукция, синтез. В процессе обработки эмпирической информацией, использовались инструменты статистического анализа.

\section{Основная часть}

В опросе населения, организованном Банком России 2021 году с целью оценки уровня доверия к безопасности финансовых технологий и сервисов [Опросы Банка России, 2021], участвовали две группы респондентов - физические и юридические лица. Значения индекса доверия физических лиц, полученные по результатам опросов, составили 53,8\% - для ЦФО и $52,2 \%$ - для Белгородской области. Эти значения оказались несколько выше общероссийского уровня $-51,9 \%$ (рис. 1 ).

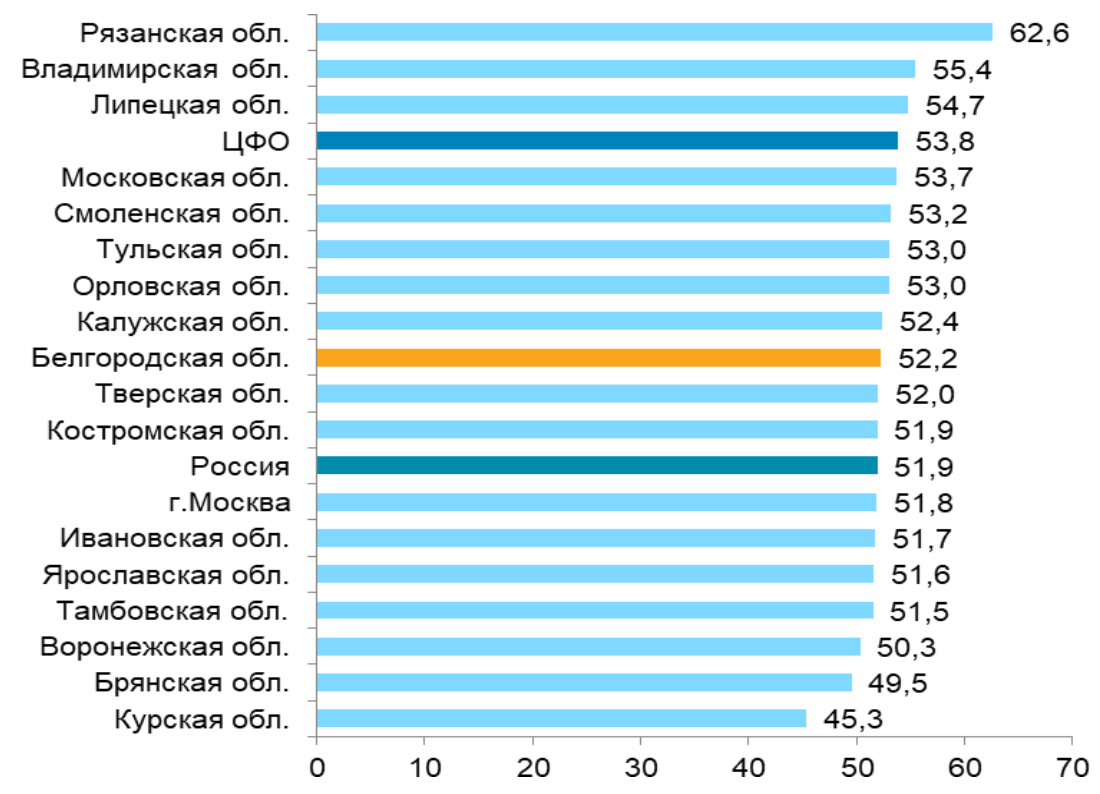

Рис. 1. Уровень доверия физических лиц, в процентах

Fig. 1. The level of trust of individuals, in percent 
В целом по ЦФО наибольший уровень доверия демонстрировали мужчины с высшим образованием и относительно высоким уровнем жизни. Женщины выразили меньший уровень доверия к безопасности финансовых технологий и сервисов. В разрезе возрастных категорий для большинства регионов ЦФО, в том числе и для Белгородской области, наиболее высокий уровень доверия оказался характерным для группы населения 15 лет - 24 года (16 из 18 регионов), что может объясняться большей цифровой грамотностью и технологической продвинутостью этой возрастной категории. Меньший уровень доверия выразили респонденты старше 25 лет и пожилое население.
Исследование также выявило, что большая часть респондентов $(67,8 \%)$ за последний год не сталкивалась со случаями мошенничества, направленными на хищение денежных средств с использованием электронных сервисов. Уровень доверия среди этой категории ожидаемо оказался выше, чем среди респондентов, столкнувшихся с мошенническими действиями.

Установленный по результатам опроса уровень доверия юридических лиц к финансовым институтам и сервисам составил $58,4 \%$ в ЦФО и $55,5 \%$ в Белгородской области, что выше среднероссийского значения $-55,1 \%$ (рис. 2).

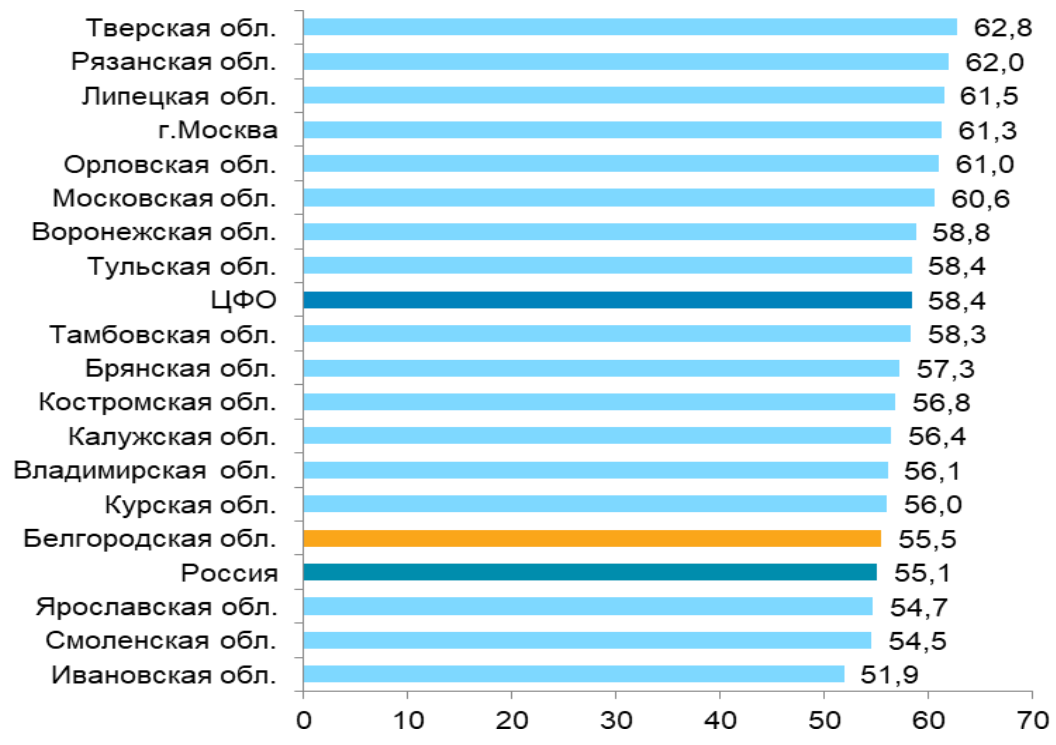

Рис. 2. Уровень доверия юридических лиц, в процентах Fig. 2. The level of trust of legal entities, in percent

Со случаями мошеннических действий, направленных на хищение денежных средств, в ЦФО сталкивались 22,9\% опрошенных предпринимателей, а в Белгородской области 23,1\%. При этом, в большинстве случаев кредитные организации предпринимали необходимые действия, направленные на защиту денежных средств своих клиентов.

Если обобщить итоги проведѐнного опроса, можно резюмировать, что большая часть респондентов - физических и юридических лиц, доверяют финтеху. Однако сложившийся уровень доверия нельзя назвать достаточным, если его рассматривать с позиции перспектив устойчивого роста использования высокотехнологичных сервисов конечными потребителями, учитывая, что доля респондентов, выразивших свое недоверие, тоже оказалась немалой.

Для эффективного функционирования и развития цифрового финансового пространства необходим рост доверия к безопасности финансовых инноваций. Такой рост может иметь устойчивый харак- 
тер на средне- и долгосрочном горизонте при условии ответственного поведения как со стороны финансовых организаций, внедряющих ноу-хау в линейку своих продуктов, так и со стороны конечных потребителей финансовых услуг. Важным условием здесь также является пропорциональное регулирование финтеха, которое будет, с одной стороны, поддерживать стабильность финансовой системы и защищать права потребителей, а с другой содействовать развитию и внедрению цифровых инноваций.

Ответственное поведение и добросовестность финансовых организаций как поставщиков высокотехнологичных услуг, прежде всего, выражается в стремлении обеспечить функциональную надежность и информационную безопасность инновационных сервисов, а также в соблюдении этических принципов взаимоотношений с клиентами. Эти принципы включают в себя открытость, порядочность, доведение до клиента всех существенных характеристик услуги, невозможность введения потребителей в заблуждение. Их учет в корпоративной культуре финансовых организаций способствует сокращению недобросовестных практик и повышает уровень доверия потребителей, в том числе и к безопасности инновационых сервисов и услуг.

Также уровень доверия к безопасности финансовых технологий в значительной мере зависит от ответственного и рационального поведения конечных потребителей финансовых услуг. Фундамент такого поведения формирует финансовоцифровая грамотность населения, сочетающая в себе соответствующие знания, установки и навыки. И в этой сфере мы можем наблюдать достаточно неоднозначную картину.

Так, в исследовании, проведенном Национальным агентством финансовых исследований (НАФИ) по итогам 2020 года [Исследование НАФИ, 2021], с одной стороны, отмечена положительная тенден- ция - рост доли населения с базовым уровнем цифровой грамотности при сокращении доли с начальным уровнем. С другой стороны, сделан вывод о том, что многие россияне по-прежнему обладают недостаточными знаниями и навыками в сфере цифровых технологий. Это может выступать ментальным барьером на пути широкого использования финансовых технологий в перспективе. Такой барьер приводит к формированию ошибочных поведенческих установок, основанных на боязни или неприятии нового, ограничивающих доверие к финансовым инновациям и препятствующих рациональному потребительскому выбору.

Еще одним прямым негативным проявлением недостаточного уровня финансово-цифровой грамотности потребителей финансовых услуг является уязвимость перед кибермошенниками. Полученный в этой связи отрицательный опыт способен перерасти в недоверие пострадавшей стороны к безопасности финансовых технологий, выступив еще одной причиной формирования ментального барьера на пути их широкого использования конечными потребителями. Это еще раз подтверждает высокую степень актуальности задачи Банка России по повышению киберграмотности граждан и бизнеса и обеспечению безопасности использования финансовых технологий. Более того, особенную важность данная задача приобретает в условиях роста активности мошенников, обусловленного массовым переходом граждан на дистанционный формат потребления на фоне высоких эпидемических рисков прошлого года.

Так, число финансовых операций, проведенных без согласия клиентов (ОБС) только во II квартале 2021 года, составило почти 237,0 тыс. единиц, а объем таких операций превысил 3,0 млрд рублей [Аналитика Банка России, 2021] (таблица). 
Таблица

Финансовые операции без согласия клиентов (ОБС), РФ ІІ квартал 2021

Table

Financial transactions without customer consent (TWC),

RF II quarter 2021

\begin{tabular}{|l|c|}
\hline Показатель & Значение \\
\hline Число ОБС, тыс. ед. & 237,0 \\
\hline Объем ОБС, млн руб. & 3013,7 \\
\hline Доля социальной инженерии, \% & 47,0 \\
\hline
\end{tabular}

Сохранение такой высокой статистики киберпреступлений может крайне негативно сказаться на доверии потребителей к безопасности финансовых технологий.

В целях преодоления имеющихся барьеров и формирования высокого уровня доверия потребителей к безопасности финансовых технологий Банк России проводит активную работу по следующим ключевым направлениям:

1. Осуществляет регулирование финансового рынка и высокотехнологичных сервисов в целях содействия их развитию и обеспечения информационной безопасности;

2. Защищает права потребителей финансовых услуг;

3. Повышает уровень цифровой и киберграмотности населения.

В частности, с учетом лучших зарубежных практик Банк России формирует требования к информационной безопасности и операционной надежности финансовых технологий по ключевым направлениям и задачам, предусмотренным стратегическим документом - «Основные направления развития информационной безопасности кредитно-финансовой сферы на период 2019-2021 годов». Документ включает и задачу роста доверия граждан к цифровой среде, для решения которой предлагается повышать уровень финансовой грамотности населения, формировать базовые компетенции по кибергигиене.

Также для содействия обеспечению информационной безопасности в структуре Банка России функционирует Центр мониторинга и реагирования на компью- терные атаки в кредитно-финансовой сфеpe (ФинЦЕРТ). Центр помогает оперативно реагировать на возникающие угрозы в финансовой сфере, не допускать их распространения, минимизировать потери финансовых организаций и их клиентов.

Кроме того, положительно влиять на доверие к безопасности финансовых технологий способны и меры Банка России, направленные на защиту прав потребителей финансовых услуг. В этом направлении только за последнее время разработано несколько основополагающих документов, к числу которых можно отнести:

- кодекс добросовестного поведения, разработанный в 2019 году, являющейся составной частью механизма развития культуры добросовестного поведения на финансовом рынке;

- стандарт безопасности финансовых операций, разработанный в 2021 году, совершенствующий механизм сохранности данных при проведении финансовых операций.

Помимо этого, с целью защиты прав потребителей финансовых услуг Банк России напрямую проводит работу по противодействию недобросовестным и противозаконным практикам. Так, только за II квартал 2021 года Банк России инициировал почти 12 тыс. (11 849) запросов операторам связи для принятия мер реагирования в отношении номеров телефонов, используемых в противоправных целях, а также направил запросы на проведение проверочных мероприятий и снятие с делегирования почти 1,5 тыс. (1 449) доменных имен сети Интернет, с использовани- 
ем которых осуществлялась противоправная деятельность. Наконец, за этот же период в отношении 359 доменов Банк России направил информацию в Генеральную прокуратору РФ для проведения проверочных мероприятий и последующего ограничения доступа к ним.

В этом плане Банк России также развивает сотрудничество и с IT-компаниями. Так, по запросу Банка России, компания «Huawei» ограничила гражданам России доступ к 21 приложению, нарушающему закон и представленному в магазине приложений «AppGallery». A компания «Apple» ограничила доступ к 41 такому приложению в сервисе «App Store» [Лях B.B., 2021].

Повышению уровня доверия граждан к безопасности финансовых технологий способствуют и реализуемые Банком России инфраструктурные проекты.

Основными инфраструктурными проектами, основанными на использовании цифровых технологий, в отношении которых в первую очередь Банком России устанавливаются требования информационной безопасности, являются: платформа удаленной идентификации (Единая биометрическая система); система быстрых платежей; платформа Маркетплейс; цифровой профиль клиента.

Также Банк России уделяет особое внимание повышению цифровой и киберграмотности в меняющихся реалиях.

Последние несколько лет регулятором организуются и проводятся обучающие курсы по кибербезопасности для финансовых организаций, представителей правоохранительных органов и представителей компаний, работающих в сфере информационной безопасности. Тематика киберграмотности также прочно вошла в периметр основных вопросов, освещаемых в рамках мероприятий финансовой грамотности. В этом плане наиболее массовый характер носят занятия в рамках всероссийского проекта Банка России «ОНлайн-уроки финансовой грамотности», аудитория которого включает учащихся всех уровней образования, а также людей пенсионного возраста.

\section{Заключение}

Таким образом, все предпринимаемые Банком России действия будут способствовать повышению доверия потребителей к финансовым инновациям и превращения этого доверия в фундамент для дальнейшего развития финансовых технологий и все более широкого их использования гражданами и бизнесом. В этом направлении важна координация усилий всех заинтересованных сторон, включая региональный уровень, направленных на повышение киберграмотности населения.

\section{Список литературы}

1. Опросы Банка России, 2021. Доверия к безопасности финансовых технологий и сервисов.

2. Аналитика Банка России, 2021. Обзор отчетности об инцидентах информационной безопасномти при переводе денежных средств. II квартал 2021 года // сайт Банка России: https://www.cbr.ru/analytics/ib/review_2q_2021/. (дата обращения 12.09.2021)

3. Исследование Национального агентства финансовых исследований (НАФИ), 2021. Цифровая грамотность россиян // сайт НАФИ: https://nafi.ru/analytics/vynuzhdennayatsifrovizatsiya-issledovanie-tsifrovoy-

gramotnosti-rossiyan-v-2021-godu/. (дата обращения 12.09.2021)

4. Лях В.В., 2021. Финансовые пирамиды все чаще появляются всоцсетях // Интервью агентству Прайм директора департамента противодействия недобросовестным практикам ЦБ РФ Лях. В.В. Сайт Банка России: http://www.cbr.ru/press/event/?id=11097\#highlig $\mathrm{ht}=\% \mathrm{D} 0 \% \mathrm{~B} 8 \% \mathrm{D} 0 \% \mathrm{BD} \% \mathrm{D} 1 \% 82 \% \mathrm{D} 0 \% \mathrm{~B} 5 \% \mathrm{D} 1$ $\% 80 \% \mathrm{D} 0 \% \mathrm{~B} 2 \% \mathrm{D} 1 \% 8 \mathrm{C} \% \mathrm{D} 1 \% 8 \mathrm{E}$. (дата обращения 12.09.2021)

5. Стратегия развития национальной платежной системы на 2021-2023 годы // сайт Банка России: https://www.cbr.ru/. (дата обращения 12.09.2021)

\section{References}

1. Polls of the Bank of Russia (2021). Confidence in the security of financial technologies and services (in Russian) 
2. Analytics of the Bank of Russia (2021). Review of reporting on information security incidents when transferring funds. II quarter of 2021 // website of the Bank of Russia: https://www.cbr.ru/analytics/ib/review_2q_2021/( accessed 12.09.2021). (in Russian)

3. Research by the National Agency for Financial Research (NAFI), 2021. Digital literacy of Russians // NAFI website: https://nafi.ru/analytics/vynuzhdennayatsifrovizatsiya-issledovanie-tsifrovoygramotnosti-rossiyan-v-2021-godu. (accessed 12.09.2021). (in Russian)

4. Lyakh V.V (2021). Financial pyramids are increasingly appearing in social networks // Interview to the Prime Agency of the Director of the Department of Counteraction to Unfair Practices of the Central Bank of the Russian Federation Lyakh. V.V. Bank of Russia website: http://www.cbr.ru/press/event/?id=11097\#highlig $\mathrm{ht}=\% \mathrm{D} 0 \% \mathrm{~B} 8 \% \mathrm{D} 0 \% \mathrm{BD} \% \mathrm{D} 1 \% 82 \% \mathrm{D} 0 \% \mathrm{~B} 5 \% \mathrm{D} 1$ $\% 80 \% \mathrm{D} 0 \% \mathrm{~B} 2 \% \mathrm{D} 1 \% 8 \mathrm{C} \% \mathrm{D} 1 \% 8 \mathrm{E}$. (accessed 12.09.2021)

5. Strategy for the development of the national payment system for 2021-2023 // Bank of Russia website: https://www.cbr.ru. (accessed 12.09.2021)

Информация о конфликте интересов: авторы не имеют конфликта интересов для декларации.

Conflicts of Interest: the author has no conflict of interest to declare.
Тимоничева Ирина Николаевна, заместитель начальника Главного управления Центрального банка Российской Федерации по Центральному федеральному округу, (Москва, Россия)

Irina N. Timonicheva, Deputy Head of the Main Department of the Central Bank of the Russian Federation for the Central Federal District, (Moscow, Russia)

Яновский Владимир Валериевич, кандидат экономических наук, руководитель направления Отделения по Белгородской области Главного управления Центрального банка Российской Федерации по Центральному федеральному округу, проспект Славы, 74, Белгород, 308000, Россия

Vladimir V. Yanovskiy, Candidate of Economic Sciences, Head of the Division for the Belgorod Region of the Main Directorate of the Central Bank of the Russian Federation for the Central Federal District, Slavy Avenue, 74, Belgorod, 308000, Russia

Бережной Анатолий Сергеевич, заместитель начальника экономического отдела Отделения по Белгородской области Главного управления Центрального банка Российской Федерации по Центральному федеральному округу, проспект Славы, 74, Белгород, 308000, Россия

Anatoly S. Berezhnoy, Deputy Head of the Economic Department of the Branch for the Belgorod Region of the Main Directorate of the Central Bank of the Russian Federation for the Central Federal District, 74 Slavy Avenue, Belgorod, 308000, Russia 